\title{
Coordinated or Uncoordinated Monetary Policy under a Regime of Flexible Exchange Rates? - The Power in Decision Making
}

\author{
Rainer Frey \\ Deutsche Bundesbank
}

\begin{abstract}
The analysis deals with the conditions under which coordination is attractive to a country in the flexible exchange-rate system. In particular, great weight is attached to the design of a common policy-decision council. The starting point is the BarroGordon approach, which is extended to address a regime of flexible exchange rates. For this purpose, the monetary transmission process - the Lucas-type supply curve is modified. The welfare criterion of the analysis is the expected loss. Losses arise owing to output-supply shocks and nominal-exchange-rate shocks. In the study, two types of coordinated equilibria and the Nash equilibrium are addressed. The results depend on the relative sizes of the countries and their importance in the policycoordination process. In addition, the degree of labour mobility affects the results.
\end{abstract}

- JEL classification: E52, E58, E61, F33

- Keywords: Flexible exchange rates, Monetary policy, Policy coordination, Voting powers

\section{Introduction}

Exchange-rate regimes have been broadly discussed in the past and were readdressed, in particular, in connection with the launch of the European monetary union (EMU) in the late 1980s and the early 1990s. As for a currency union, welfare criteria should be formally worked out for the assessment of a regime of flexible

*Corresponding address: Rainer Frey, Deutsche Bundesbank, Economics Department, Wilhelm-EpsteinStraße 14, 60431 Frankfurt am Main, Germany, Tel: 0049699566 2456, Fax: 0049699566 2982, Email: rainer.frey@bundesbank.de

(C2006-Center for International Economics, Sejong Institution, All Rights Reserved. 
exchange rates.

The regime of flexible exchange rates is one of the most frequent currency regimes. Rates float between many industrial countries and trading blocs. Since 1990 , it has been possible to observe a marked shift from pegged exchange rates to flexible rates. In the 'de facto classification' of the IMF (2003, p 8), in 1990 just $20.1 \%$ of the countries with IMF membership had floating regimes. By 2001, the number had gone up to $44.1 \%$. Intermediate exchange-rate regimes, in particular, suffered a loss of popularity.

Game-theoretic analyses in open economies are not new. Starting out from a Keynesian model framework, Hamada (1974) looks at the choice of exchange-rate regimes in a game-theoretic approach and considers Nash and Stackelberg solutions. In the incentive approach of Hamada (1998), a currency regime is chosen; afterwards, policy interplays take place. Hamada shows the impact of the choice of the exchange-rate regime on the pursuance of national objectives. For flexible rates, Rogoff (1985b) finds that cooperation does not increase the welfare of the cooperating countries in any case because cooperation strengthens a central bank's credibility problem vis-à-vis the private sector. Oudiz and Sachs (1985) distinguish between open-loop and closed-loop behaviour and between noncooperative and cooperative decisions. However, the article does not consider the relevance of different shock scenarios. In addition, Canzoneri and Gray (1985) investigate monetary-policy games, Stackelberg and Nash equilibria, after a common external shock. In the minimisation approach of Gros and Lane (1992), the optimal degree of intervention by the central bank, ie the weighting of the exchange-rate objective in the loss function, depends on the size of the different kinds of output and exchange-rate shocks and on the interventions of the foreign central bank. The relevance of price setting is taken up by Canzoneri, Cumby and Diba (2001). The gains from coordination depend on the size and correlation of shocks. For flexible rates, and under flexible and sticky prices, Obstfeld and Rogoff (2002) find in their welfare-maximisation model that the role of international policy coordination is very limited. This outcome even holds in the face of significant economic integration.

In the literature, the assessment of international policy coordination under flexible and fixed exchange rates has often been limited to a comparison of the welfare in one policy-coordination scenario with that in the Nash equilibrium. However, the constitution of a common policy-decision board can be designed in different ways. It is possible to imagine that a country's weight on the board 
corresponds to its relative economic country size, but for political reasons, it is also possible that countries which differ in size or in economic importance accept the same weighting in the decision-making process. Below, it is shown that the composition of the common board has an impact on how attractive coordinated policies are to a country. With regard to a currency union, the relevance of the design of the decision-taking process has already been major issue in several articles. Aksoy, de Grauwe and Dewachter (2002) distinguish between three voting procedures: consensus rule on the governing council, H'intermediate $(E(\beta))$ Von Hagen (1999 and 2000) shows that, if the ECB Council decisions are taken by majority vote, the mean voter obtains his preferred inflation rate. Additionally, Dixit (2001) considers a central bank that commits to a weighted average of the most preferred policy rules of the member countries. In Gruner (1999), if the central bank considers aggregate variables of the currency area, one symmetric subgame-perfect Nash equilibrium arises. Provided the monetary decisions are taken by the majority vote of national central-bank presidents, two equilibria emerge.

In addition, the article introduces international labour migration into the assessment of policy coordination. As migration has a stabilising impact on an economy hit by shocks, the desirability of international policy coordination is affected by the degree of labour mobility. Mundell (1961) already incorporates labour mobility when he assesses the regime of fixed exchange rates in comparison with that of flexible rates in the face of output demand shocks.

The approach below is referred to as the 'standard' or 'classical' monetary-policy model, or the 'Barro-Gordon' approach (see Gray (1976), and Barro and Gordon (1983a and 1983b)). Within this framework, the national welfare function/the central-bank objective function is a loss function that is squared in the deviations of inflation and output from their targets. The central bank minimises its objective function while it considers the Phillips-curve relationship as a constraint. The relative simplicity of the approach allows us to incorporate several aspects, while retaining the clarity of the mechanisms and results. ${ }^{1}$ The study extends this monetary-policy framework to the regime of flexible exchange rates. Under

\footnotetext{
${ }^{1}$ Another workhorse model in the field of open economies is that of Obstfeld and Rogoff (1995 and 1998). They start out from the maximisation of the utility of a representative agent. However, in reality, macroeconomic policies like monetary policy and the choice of exchange-rate regimes are assessed by the performance with respect to macroeconomic variables. Also, the recent literature provides us with a microeconomic grounding of the Barro-Gordon approach. In the derivations of the quadratic loss function, a second-order approximation is applied to the utility function of a representative consumer (see Rotemberg and Woodford (1999), Woodford (2001), Galí and Monacelli (2002), and Clarida, Galí and Gertler (2002)).
} 
flexible rates, movements of the nominal exchange rate which are combined with changes in the real exchange rate trigger output effects. As the central bank can affect the exchange rate, this relationship may be exploited by the monetary authority. Thus, the Phillips-curve relationship, which describes the impact of monetary policy on output supply is enforced under flexible rates.

In Section 2, the framework is introduced. Section 3 considers the effects of labour migration, and Section 4 determines the optimal inflation-rate rules in the case of coordinated and non-coordinated policies. In Section 5, welfare analyses for different shock scenarios are deduced. Finally, Section 6 offers some conclusions.

\section{The Model}

First, the Barro-Gordon setting is introduced. The objective function of the domestic central bank is a quadratic social loss function depending on the inflation rate and on the output level. Deviations from the socially desirable targets imply losses: ${ }^{2}$

$$
L_{t}=\frac{1}{2}\left[\left(\pi_{t}-\pi^{*}\right)+b\left(y_{t}-y^{*}\right)\right]
$$

where $\pi_{t}$ and $y_{t}$ are the inflation rate (the difference of the price levels in logarithms in period $t$ and in period $t-1$ ) and the logarithms of the output level in periods $t, \pi^{*}$ and $y^{*}$ are the socially desirable targets, and $b>0$ is a weighting parameter.

The constraint faced by the central bank is the Phillips curve. In a closed economy, the Phillips-curve equation is given by ${ }^{3}$

$$
y_{t}=\alpha\left(\pi_{t}-\pi_{t}^{e}\right)+\varepsilon_{t}
$$

where $\alpha$ is a positive coefficient, $\pi_{t}^{e}$ is the inflation rate that is expected in period $t-1$ for period $t$, and $\varepsilon_{t}$ is a iid supply shock with mean 0 and variance $\sigma^{2}$.

As in Svensson (1997), the natural output level is the unconditional mean of the output level, $E\left(y_{t}\right)$. Surprise inflation and output supply shocks cause deviations

\footnotetext{
${ }^{2}$ Horowitz (1987) addresses the properties of the quadratic social loss function.

${ }^{3}$ Here, output persistence is not considered. Output persistence would require the incorporation of the lagged output level (see Lockwood, Miller and Zhang (1998)).
} 
from the natural output level.

The market participants have rational expectations:

$$
\pi_{t}^{e}=E_{t-1} \pi_{t}
$$

where $E_{t-1}$ is an operator of expectations being conditional upon information available in period $t-1$.

In the case of flexible rates, the inflation-output trade-off differs from that in a closed economy since monetary policy affects the output level additionally via the exchange rate. Under flexible exchange rates, changes in monetary policy are accompanied by immediate changes in the nominal exchange rate. By contrast, prices on the goods and labour market are sticky. Thus, the central bank can influence the real prices and the real exchange rate, and these gradually return to their long-term levels towards the end of the period. The real exchange rate may be interpreted as a measure of competitiveness and changes in the real exchange rate have an effect on the output level (see Buiter and Miller (1982)). ${ }^{4}$

Taking into account these output effects due to movements of the real exchange rate, the short-term trade-off between output and inflation is ${ }^{5}$

$$
y_{t}=\alpha\left(\pi_{t}-\pi_{t}^{e}\right)+\delta r_{t}+\varepsilon_{t}
$$

with $\delta=(1-n) \alpha$.

The parameter $\delta$ is a transmission coefficient that describes the effects of deviations of the real exchange rate from its long-term level on the output level. It depends on the size of the country $(n)$ and the inflation-output trade-off parameter in a closed economy $(a)$ : The smaller the country, the more important are the output effects triggered by movements of the real exchange rate. ${ }^{6}$

As is derived in the Appendix, the real exchange rate at the beginning of a

\footnotetext{
${ }^{4}$ Obstfeld and Rogoff (1999, p 7-11) find that movements of the nominal exchange rate are highly correlated with the relative competitiveness of a country ( 0.7 or higher for Germany, Italy, Japan, UK and the USA; sample: 1982-1998).

${ }^{5}$ For a derivation of this equation, please refer to the Appendix.

${ }^{6}$ In a very small country, the effect may be reduced since people are aware of the role which the large neighbouring country plays for their economy and given that, they are aware of the major importance of the exchange rate for domestic prices and wages.
} 
period is a function of surprise inflation at home and abroad, and of nominal exchange-rate shocks: ${ }^{7}$

$$
r_{t}=\left[\left(\pi_{t}-\pi_{t}^{e}\right)-\left(\pi_{t}^{a}-\pi_{t}^{a e}\right)\right]+\eta_{t}
$$

where $\pi_{t}^{a}\left(\pi_{t}^{a e}\right)$ is the actual (expected) foreign inflation rate, and $\eta_{t}$ is a iid speculative shock to the nominal exchange rate in period $t$ with mean zero and variance $\left(\sigma^{\text {nom }}\right)^{2}$.

With equations (4) and (5), the output supply function may be rewritten as

$$
y_{t}=\phi\left(\pi_{t}-\pi_{t}^{e}\right)-\delta\left(\pi_{t}^{a}-\pi_{t}^{a e}\right)-\delta \eta_{t}+\varepsilon_{t}
$$

with $\phi=\alpha+\delta$,

and where $n \in[0 ; 1]$ reflects the size of the domestic country relative to the size of both countries together and $(1-n)$ is the relative size of the foreign country.

If the central bank commits to an optimal policy rule (see Kydland and Prescott (1977), and Barro and Gordon (1983b)), the expected period loss is minimised over the actual and the expected inflation rates:

$$
\min _{\pi_{t}, \pi_{t}^{e}} E_{t-1}\left(L_{t}\right)
$$

subject to equations (1), (3) and (6).

The first-order conditions are

$$
\begin{aligned}
& \pi_{t}-\pi^{*}+b \phi\left(y-y^{*}\right)+\theta_{t-1}=0, \\
& -E_{t-1}\left[b \phi\left(y-y^{*}\right)\right]-\theta_{t-1}=0,
\end{aligned}
$$

where $\theta_{t-1}$ is the Lagrange multiplier for the constraint $\pi_{t}^{e}=E_{t-1} \pi_{t}$.

We are able to deduce the following relationship from the first-order conditions:

$$
\pi_{t}-\pi^{*}+b \phi\left(y_{t}-y^{*}\right)-E_{t-1}\left[b \phi\left(y_{t}-y^{*}\right)\right]=0 .
$$

Taking expectations at $t-1$, we find that

${ }^{7}$ Persson and Tabellini (1996, p 6) also consider the impact of speculative nominal-exchange-rate shocks on monetary policy. 


$$
E_{t-1} \pi_{t}=\pi^{*}
$$

with $E_{t-1}\left(\pi_{t}^{a}-\pi_{t}^{a e}\right)=0$.

With equations (6), (11) and (12), the optimal inflation-rate rule of the domestic central bank may be written as

$$
\pi_{t}=\pi^{*}-\frac{b \phi}{1+b \phi^{2}} \varepsilon_{t}-\frac{b \phi \delta}{1+b \phi^{2}} \eta_{t}+\frac{b \phi \delta}{1+b \phi^{2}}\left(\pi_{t}^{a}-\pi_{t}^{a e}\right) .
$$

The derivation of the optimal inflation rate rule abroad is analogous to that at home.

Below, we continue to mark the foreign variables with the exponent ' $a$ '. Then, the loss function of the foreign central bank with targets for inflation and output which equal those in the home country may be written in the following manner:

$$
L_{t}^{a}=\frac{1}{2}\left[\left(\pi_{t}^{a}-\pi^{*}\right)^{2}+b^{a}\left(y_{t}^{a}-y^{*}\right)^{2}\right]
$$

and the monetary transmission process abroad is

$$
y_{t}^{a}=\phi^{a}\left(\pi_{t}^{a}-\pi_{t}^{a e}\right)-\delta^{a}\left(\pi_{t}-\pi_{t}^{e}\right)-\delta \eta_{t}+\varepsilon_{t}^{a} .
$$

As at home, the private sector forms rational expectations about the foreign inflation rate:

$$
\pi_{t}^{a e}=E_{t-1} \pi_{t}^{a}
$$

Welfare maximisation which is analogous to that of the home central bank leads to the optimal inflation-rate rule abroad:

$$
\pi_{t}^{a}=\pi^{*}-\frac{b^{a} \phi^{a}}{1+b^{a}\left(\phi^{a}\right)^{2}} \varepsilon_{t}^{a}+\frac{b^{a} \phi^{a} \delta^{a}}{1+b^{a}\left(\phi^{a}\right)^{2}} \eta_{t}+\frac{b^{a} \phi^{a} \delta^{a}}{1+b^{a}\left(\phi^{a}\right)^{2}}\left(\pi_{t}-\pi_{t}^{e}\right),
$$

with $\phi^{a}=\alpha^{a}+\delta^{a}$ and $\delta^{a}=n \alpha^{a}$. 


\section{Monetary Policy in an Open Economy and Labour Mobility}

In the field of exchange-rate regimes, Mundell's (1961) paper on optimum currency areas has already addressed the relevance of labour mobility.

To deduce the implications of labour mobility for economies and national welfare levels, it is first necessary to explain the way in which the labour market is related to the goods market. It is assumed that long-term output supply is accompanied by full employment. Consequently, negative output-supply shocks cause unemployment while positive supply shocks result in excess labour demand. Migration relieves the labour market of the country in which a negative output shock occurs. Of course, when there has been full employment in the other country before, the inflow of migrants creates unemployment provided wages are rigid (see also Beine and Docquier (1998, p $241 \mathrm{f}))^{8}{ }^{8}$

Below, it is assumed that the degree of labour mobility is the same in both countries: ${ }^{9}$

$$
\begin{gathered}
\varepsilon_{t}=(u n+(1-u)) \varepsilon_{t}^{\prime}+u(1-n) \varepsilon_{t}^{a^{\prime}}, \\
\varepsilon_{t}^{a}=(u(1-n)+(1-u)) \varepsilon_{t}^{a^{\prime}}+u n \varepsilon_{t}^{\prime},
\end{gathered}
$$

where $\varepsilon_{t}\left(\varepsilon_{t}^{a}\right)$ is the effect of supply shocks at home (abroad) after migration has finished, $\varepsilon_{t}^{\prime}\left(\varepsilon_{t}^{a^{\prime}}\right)$ is the supply shock that initially occurs at home (abroad), and $u \in[0 ; 1]$ is the degree of labour mobility: $u=0$ stands for no labour mobility and $u=1$ means perfect labour mobility.

In the case of perfect labour mobility $(u=1)$, the negative effects of the shocks that initially occur in one country are relocated to both countries in proportion to the relative country size.

\footnotetext{
${ }^{8}$ Frey (2004) models the occurrence of the spill-over effects from migration with a lag.

${ }^{9}$ This presentation is similar to Bayoumi (1994). However, Bayoumi does not consider the relative sizes of the countries. In Bayoumi, the immigration of labour force increases the output level in the region with excess demand for labour but labour-force emigration does not affect the output level in the country that faces unemployment.
} 


\section{The Cooperative and Nash Equilibriums of Monetary Policy under Flexible Exchange Rates}

We distinguish two types of equilibria: the coordinated equilibrium and the Nash equilibrium. ${ }^{10}$ In the coordinated equilibrium, both countries are aware of the interactions of their policies and internalise the international spill-over effects. By contrast, the national central banks do not take into account the fact that their behaviour affects that of the other country in the Nash equilibrium.

If the two central banks cooperate, the joint loss is minimised. The joint loss function is the sum of the national losses:

$$
L_{t}^{\text {sum }}=w L_{t}+(1-w) L_{t}^{a}
$$

Two types of weighting of the losses are addressed. The weights may correspond to the relative sizes of the countries, $w=n$, or both countries may have the same weights in decision-making, $w=0.5$.

The joint loss function is minimised over the actual and expected domestic and foreign inflation rates:

$$
\min _{\pi_{t}, \pi_{t}^{e}, \pi_{t}^{a}, \pi_{t}^{a t}} E_{t-1}\left(L_{t}^{\text {sum }}\right)
$$

subject to equations (1), (3), (6), (14), (15), (16) and (20).

This yields four first-order conditions:

$$
\begin{aligned}
& w\left(\left(\pi_{t}-\pi^{*}\right)+b \phi\left(y_{t}-y^{*}\right)\right)-(1-w)\left(b^{a} \delta^{a}\left(y_{t}^{a}-y^{*}\right)\right)+\theta_{t-1}=0, \\
& -w E_{t-1}\left(b \theta\left(y_{t}-y^{*}\right)\right)+(1-w) E_{t-1}\left(b^{a} \delta^{a}\left(y_{t}^{a}-y^{*}\right)\right)-\theta_{t-1}=0, \\
& (1-w)\left(\left(\pi_{t}^{a}-\pi^{*}\right)+b^{a} \phi^{a}\left(y_{t}^{a}-y^{*}\right)\right)-w\left(b \delta\left(y_{t}-y^{*}\right)\right)+\theta_{t-1}^{a}=0, \\
& -(1-w) E_{t-1}\left(b^{a} \theta^{a}\left(y_{t}^{a}-y^{*}\right)\right)+w E_{t-1}\left(b \delta\left(y_{t}-y^{*}\right)\right)-\theta_{t-1}^{a}=0,
\end{aligned}
$$

where $\theta_{t-1}$ is the Lagrange multiplier for the constraint $\pi_{t}^{e}=E_{t-1} \pi_{t}$ and $\theta_{t-1}^{a}$ is that for $\pi_{t}^{a e}=E_{t-1} \pi_{t}^{a}$.

\footnotetext{
${ }^{10}$ Another possible outcome is the Stackelberg equilibrium, in which the domestic (foreign) central bank considers the reaction function of the foreign (domestic) country in its optimisation.
} 
By the first-order conditions, we can calculate the optimal inflation rates at home and abroad:

$$
\begin{aligned}
\pi_{t} & =\pi^{*}-\frac{(1-w)\left(w b \phi \delta+(1-w) b^{a}\left(\delta^{a}\right)^{2}+w b b^{2} \delta\left(\phi^{2}-\delta^{a}\right)\left(\phi \phi^{a}-\delta \delta^{a}\right)\right)}{f} \eta_{t} \\
& -\frac{w(1-w) b\left(\phi+b^{a} \phi^{2}\left(\phi \phi^{a}-\delta \delta^{a}\right)\right.}{f} \varepsilon_{t}+\frac{(1-w) b^{a}\left((1-w) \delta^{a}+w b \delta\left(\delta \delta^{a}-\phi \phi^{a}\right)\right.}{f} \varepsilon_{t}^{a}, \\
\pi_{t}^{a} & =\pi^{*}-\frac{w\left((1-w) b^{a} \phi^{a} \delta^{a}+w b \delta^{2}+(1-w) b b^{a} \delta^{a}(\phi-\delta)\left(\phi \phi^{a}-\delta \delta^{a}\right)\right.}{f} \eta_{t} \\
& -\frac{w(1-w) b^{a}\left(\phi^{a}+b \phi\left(\phi \phi^{a}-\delta \delta^{a}\right)\right.}{f} \varepsilon_{t}^{a}+\frac{w b\left(w \delta+(1-w) b^{a} \delta^{a}\left(\delta \delta^{a}-\phi \phi^{a}\right)\right.}{f} \varepsilon_{t},
\end{aligned}
$$

with $f=w(1-w)\left(1+b \phi^{2}+b^{a}\left(\phi^{a}\right)^{2}+b b^{a}\left(\phi \phi^{a}-\delta \delta^{a}\right)^{2}\right)+w^{2} b \delta^{2}+(1-w)^{2} b^{a}\left(\delta^{a}\right)^{2}$.

The private sector expects the inflation rates to equal their desired targets:

$$
\pi_{t}^{e}=\pi_{t}^{a e}=\pi^{*}
$$

The Nash equilibrium is described by the point of intersection of the reaction functions of the central banks - the optimal inflation-rate rules at home and abroad (equations (13) and (17)). The following domestic and foreign inflation rates are chosen:

$$
\begin{gathered}
\pi_{t}=\pi^{*}-\frac{b \phi\left(1+b^{a}\left(\phi^{a}\right)^{2}\right)}{1+b \phi^{2}+b^{a}\left(\phi^{a}\right)^{2}} \varepsilon_{t}-\frac{b \phi \delta^{a} b \phi^{a}}{1+b \phi^{2}+b^{a}\left(\phi^{a}\right)^{2}} \varepsilon_{t}^{a}-\frac{b \phi \delta\left(1+b^{a}\left(\phi^{a}\right)^{2}-b^{a} \phi^{a} \delta^{a}\right)}{1+b \phi^{2}+b^{a}\left(\phi^{a}\right)^{2}} \eta_{t} \\
\pi_{t}=\pi^{*}-\frac{b^{a} \phi^{a}\left(1+b \phi^{a}\right)}{1+b \phi^{2}+b^{a}\left(\phi^{a}\right)^{2}} \varepsilon_{t}^{a}-\frac{b^{a} \phi^{a} \delta^{a} b \phi}{1+b \phi^{2}+b^{a}\left(\phi^{a}\right)^{2}} \varepsilon_{t}-\frac{b^{a} \phi^{a} \delta\left(1+b \phi^{2}-b \phi \delta\right)}{1+b \phi^{2}+b^{a}\left(\phi^{a}\right)^{2}} \eta_{t} .
\end{gathered}
$$

Again, the expected inflation rates at home and abroad equal their desired target:

$$
\pi_{t}^{e}=\pi_{t}^{a e}=\pi^{*}
$$




\section{Results}

Losses are caused by shocks at home and abroad, which lead to the output level and the inflation rate deviating from their targets. The expected loss depends on the future behaviour of the shocks. For convenience, the central banks expect the behaviour of shocks to be the same for all future periods. This allows a limitation of the analysis to the loss that is expected for period $t$ in period $t-1$. Because the central banks conduct stabilisation policy in the model, an assessment of the flexible-rate arrangement requires consideration of the expected indirect loss, which implies the consideration of central-bank policy actions. This means that the optimal inflation-rate rules, which are linear in the random variables, have to be plugged into the expected loss function, and the expected indirect loss is a linear function of the variances of the output shocks at home and abroad, and of nominal exchange-rate shocks.

The welfare considerations rely on the derivatives of the expected indirect loss function with respect to these variance terms.

Owing to the complexity of the results, the presentation is limited to threedimensional graphs. The visualisation of the results in graphs requires the fixing of parameter values. ${ }^{11}$ Below, $b=b^{a}=0.5, \alpha=\alpha^{a}=5$ and $h=h^{a}=0.3 . b=0.5\left(b^{a}=0.5\right)$ means that the central bank at home (abroad) attaches half the weight of the inflation objective to the output objective. ${ }^{12} \alpha=3$ ( $\alpha^{a}=3$ ) describes the assumed inflationoutput trade-off in the home (foreign) country; an increase of $1 \%$ in domestic (foreign) surprise inflation makes the domestic (foreign) output level increase by $3 \%$.

\section{A. Welfare analysis in the presence of output shocks}

First, output shocks at home are investigated.

Starting out from size-weighted voting powers in the case of coordination, in the absence of labour mobility, the differences between expected losses that arise in the non-cooperative and the cooperative equilibria are highest for countries of similar

\footnotetext{
${ }^{11}$ See the Appendix for figures showing the ratios of differences between the expected losses in the Nash and coordinated-policy equilibria to the expected losses in the coordinated-policy equilibria (only provided for size-weighted decision powers).

${ }^{12}$ These output-preference parameters are also chosen by de Grauwe, Dewachter and Aksoy (1999) in their EMU simulation model. Broadbent and Barro (1997) found this to be 1/3 in the US between 1954 and 1994.
} 
size (see Figure 1). Then, cooperation is especially fruitful. However, for higher degrees of labour mobility, the maximum-loss difference for $n$ is found to be higher than 0.5. Under perfect labour mobility, the maximum loss appears when the relative size of the domestic country, $n$, is around 0.8 . Thus, with labour mobility, and provided that the country does not become dominantly large, the larger the country is the more it is interested in coordinated monetary policies in the presence of output shocks at home. This is because a large country has a strong weight in a common board's decisions on the monetary policies of the two countries and thus the exchange rate. By dominating monetary-policy decisions, it can keep its losses down. Here, in the case of labour mobility, the foreign country is hit by the spillover effects of domestic output shocks. Thus, not only the domestic but also the foreign country would like its currency to depreciate or appreciate. Then, coordinated monetary policies avoid excessive inflation or deflation in the two countries. If the relative size of the domestic country exceeds a particular value, the comparative advantage of coordinated policies over uncoordinated policies diminishes since exchange-rate movements become less and less relevant to the large country. However, the coordination of monetary policies is at the expense of a small foreign country. This country would be better off in the Nash equilibrium.

The results are different if both countries have the same powers in the decisiontaking process. Figure 2 shows that the difference in the losses can become negative. Since the figure displays the difference between the expected losses in the case of non-cooperative policies and in coordinated policies, a negative value indicates that the loss under coordination exceeds that in the Nash equilibrium and the country is better off in the non-cooperative equilibrium. Without labour mobility, a small country prefers the coordination of the monetary policies while a large country would like the Nash equilibrium. This can be explained in the

\section{Figure 1 and 2.}

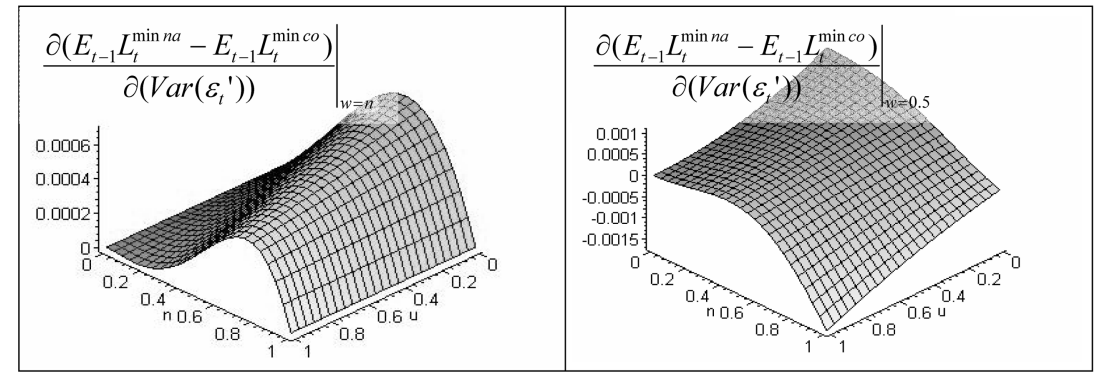


following way. If the domestic country is hit by a shock and conducts stabilisation policy, it simultaneously destabilises the foreign economy. Consequently, the neighbouring country has an incentive to take measures to counteract this spill-over effect. However, in return, the measures taken abroad would moderate the effects of the stabilisation policy at home. Here, a small domestic country can gain under cooperation if it is given the same weight in the decision-taking process. Then, the stabilisation costs due to the shocks at home are relocated to both countries, the marginal losses are the same in both countries and the sum of the expected national losses is minimised. Since movements of the exchange rate have a greater effect on a small economy than on a large one, the exchange rate can play an important role in the stabilisation of the small economy. This is considered by the common monetary authority. Under perfect labour mobility, the preferences either disappear or are strengthened. Here, a very small country has neither a preference for the coordinated-policy equilibrium nor for the non-coordinated-policy equilibrium. In the presence of output shocks at home, labour mobility almost completely transmits the effects of the shocks at home to the large foreign economy. However, starting from a very small domestic country, the domestic shock becomes more important to the economies of the two countries and the domestic country develops a preference for coordinated policies as long as $n$ is relatively small, ie $n$ is around 0.5 . Since, under labour mobility, both countries are affected in the same way by the shock, and since exchange-rate movements have a greater effect on a small economy, the small domestic country has a strong incentive for making the exchange rate move to stabilise its economy. Then, coordinated policies reduce the expected loss at home, since they allow the small domestic country to rely on exchange-rate movements in agreement with the monetary-decision board to some extent. Of course, this change in the exchange rate increases the loss suffered by the large country. It can be seen from Figure 2 that a large country chooses the Nash equilibrium and that the preference is all the stronger, the higher the degree of labour mobility.

Figure 3 shows that a small country is better off in the case of an output shock abroad if the monetary policies of the two countries are not coordinated, provided the weighting of the decision powers equals the relative sizes of the countries. Under coordination, the common monetary policies are conducted with respect to the concerns of the large country and the movement of the exchange rate is stronger and thus more harmful to the small domestic country than in the Nash equilibrium. Labour mobility makes the difference between the expected losses in 
the two types of equilibria decrease, since the higher the degree of labour mobility is, the more the countries are interested in the same monetary policies.

The results change if the two countries have the same voting powers in the monetary-coordination process (see Figure 4). Here, a small country in particular is interested in coordinated monetary policies. Without labour mobility, it can use its political influence to make its neighbour reduce its own stabilisation efforts. Since the stabilisation policy of the neighbouring country destabilises the domestic economy, a moderation of the monetary-policy measures abroad reduces the loss at home. By contrast, up to perfect labour mobility, a large domestic country prefers to play Nash. Otherwise, it would have to take the concerns of the small country into account and would deviate from its optimal policy to a greater extent. With labour mobility, the smaller the domestic country is, the more it strives for coordinated monetary policies. As migration makes the economic conditions equalise in the two countries and as movements of the exchange rate are especially relevant to a small economy, cooperation allows the small country to employ the exchange-rate instrument to stabilise its economy to some extent. Then, the sum of the expected national losses is reduced, though both countries are affected by the shock in the same way. Under labour mobility, a very large domestic country has almost no preference for any regime since migration makes the effects of the shocks in the small foreign country nearly irrelevant to both economies and, thus, the national policy interests coincide.

Now, the impact of negatively correlated output shocks occurring in the two countries is considered (Figures 5 and 6). This means that the output shock at home and the one abroad differ in sign and it is assumed that they correspond in size: $\varepsilon_{t}^{a}=-\varepsilon_{t}$.

\section{Figure 3 and Figure 4.}

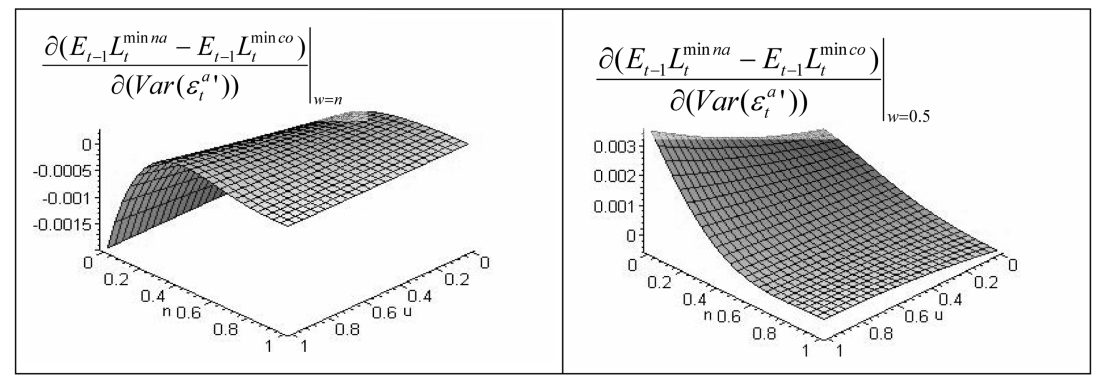


Figure 5 and Figure 6.

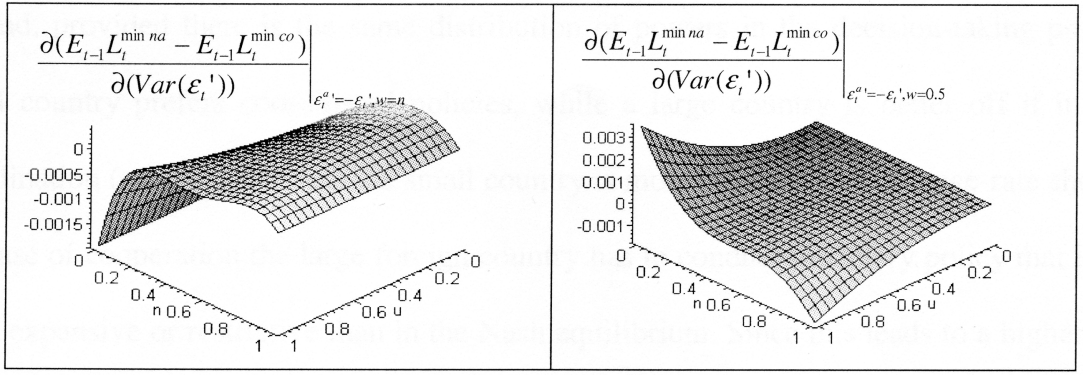

As above, the coordinated case with size-weighted-decision powers is addressed first (see Figure 5). Again, a small country could ameliorate its situation if it shifted from the coordinated-policy equilibrium to the Nash equilibrium. Although, under coordination, the exchange rate moves in the direction that is also preferred by the small country, the extent of the movement is too large with respect to the concerns of the small country. ${ }^{13}$ This is due to the fact that exchange-rate movements have a stronger effect on the economy of a small country than on that of a large country. Since, under this type of coordination, the large country dominates the decision about the size of the movement of the exchange rate, the small country can benefit from restriction of exchange-rate movement. The Nash and the coordinated-policy equilibria equalise if the degree of labour mobility increases. Then, economic conditions in the two countries become increasingly similar and, thus, the differences in their favoured policies progressively disappear. This is given, although, under perfect labour mobility, there is some movement of the exchange rate that is harmful to the small country. ${ }^{14}$

Below, both countries have the same weights in the coordinated monetarydecision-taking process (Figure 6). In the absence of labour mobility, it does not matter whether uncoordinated or coordinated policies are conducted. However, with perfect labour mobility, a small country favours cooperation. In this case, economic conditions are the same in both countries and cooperation allows the small country to induce exchange-rate movements to stabilise its economy to some extent. With the greater efficiency of the exchange-rate channel in the small

\footnotetext{
${ }^{13}$ As a reminder: as long as one country is hit by a positive shock while the other country is hit by a negative shock, both countries agree with the direction of the movement of the exchange rate.

${ }^{14}$ However, a very small country, $n$ close to 0 , still prefers non-coordinated monetary policies.
} 
country, an exchange-rate movement in the direction preferred by the small country reduces the sum of the expected national losses. Since this policy is at the expense of the welfare of the large country, the large country opts for uncoordinated monetary policies for the two countries. Thus, the higher migration is, the more the countries disagree about the movement of the exchange rate and the greater are the national preferences for uncoordinated or coordinated policies.

\section{B. Welfare analysis in the presence of nominal-exchange-rate shocks}

Here, owing to the construction of the model, the degree of labour mobility does not affect the results below.

Again, we first address coordinated monetary policies that are determined by decisions in which the weights of the countries equal their relative sizes (see Figure 7). In contrast to the scenarios of output shocks abroad and of negatively correlated output shocks, here the expected loss of the small country is higher if the two countries do not cooperate. In the case of cooperation, the high loss suffered by the small country enters the joint loss function of the two countries. By this means, despite the low weight of the loss of the small country in this function, the relatively high expected loss of this country is considered by the cooperating central banks. As a result, in the coordinated-policy equilibrium, the expected loss of the small country does not reach the level given under non-cooperative behaviour of the two central banks. In return, a large country with $n$ higher than approximately 0.7 is better off in the non-cooperative equilibrium. This is due to the fact that, in the cooperative case, belongings of the large country are 'neglected' to some extent to reduce the relatively high expected loss in the small country. The shift to coordinated monetary policies decreases the loss of the small country to a greater extent than the loss of the large neighbouring country increases, since the small country is more strongly affected by the impact of the exchange-rate shock.

Second, provided there is the same distribution of powers in the decision-taking process, a small country prefers coordinated policies, while a large country is better off if it refuses coordination (see Figure 8). As the small country is more affected by exchange-rate shocks, in the case of cooperation the large foreign country has to conduct monetary policy that is either more expansive or restrictive than in the Nash equilibrium. Since this leads to a higher loss in the large country, the large country does not like to coordinate its policy with the small country. 
Figures 7 and 8.

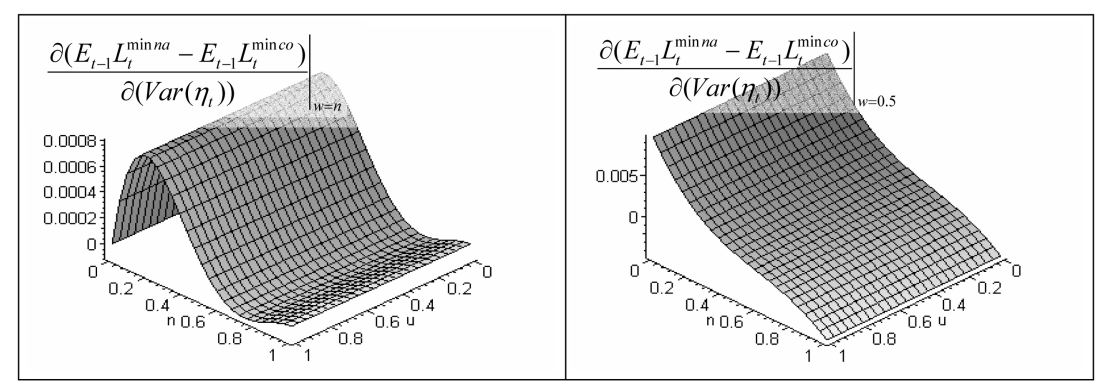

\section{Conclusions}

Above, without surprises, ie there are no shocks, no losses occur. This corresponds to Helpman (1981), who shows that equilibrium allocation of consumption is efficient in every exchange-rate setting in the absence of surprises.

Under flexible rates, the question is addressed as to whether it is better for countries to coordinate their policies or if the loss is lower in the Nash equilibrium. Two types of coordinated policies are addressed. First, the weights of the two countries in decision-taking correspond to their relative sizes. Second, both countries have the same weights. With decision weights according to the relative sizes of the countries, regardless of the output-shock scenario, the large country always has a preference for policy coordination with the small country. This is due to the strong impact of the large country on the co-ordination process. However, in the event of nominal-exchange rate shocks, if the relative size of the large country exceeds a particular value, non-coordination is more favourable to its concerns. The results are less clear if medium-sized countries are considered. In the case of output shocks at home or nominal exchange-rate shocks, a medium sized country profits from cooperation. However, if output shocks occur abroad or if there are negatively correlated output shocks, the outcome for a medium-sized country is ambiguous. In this case, a marginal preference may exist that depends on the concrete parameter values of the model. A small country benefits from coordination when there are output shocks at home or nominal-exchange-rate shocks. With output shocks abroad or negatively correlated output shocks, it can reduce its loss if it refuses to cooperate. In the analysis, labour migration makes the differences between coordinated and non coordinated policies decrease. This outcome is consistent with Obstfeld and Rogoff (2002), who find that economic 
market integration, which may be interpreted as an increase in the degree of labour mobility above, makes the Nash and the coordinated equilibria collapse.

The results partially reverse if the countries have the same power in decisionmaking. Here, the small country opts for coordinated monetary policies in all scenarios. Since the movement of the exchange rate is especially relevant to the small country, it can reduce its losses if the monetary policies of the two countries are coordinated when the weight assigned to it in the common council is the same as that of the large country. By contrast, a medium-sized country only has a clear preference for policy coordination in the case of output shocks abroad. Provided output shocks arise at home or negatively correlated output shocks occur in the two countries, the outcome for the medium-sized country is ambiguous. In the case of nominal-exchange-rate shocks, it is indifferent between policy coordination and non-coordination. Moreover, coordination is unfavourable to the large country. It is only in the case of output shocks abroad that it can slightly improve its welfare by policy coordination. In all other scenarios, it is better off in the Nash equilibrium. Thus, for any scenario, the larger the country is, the less it is interested in coordinated monetary policies with equal decision weights for both countries. Here, the higher the degree of labour mobility is, the higher is the preference for either the coordinated equilibrium or the Nash equilibrium.

\section{Acknowlegments}

I am indebted to Matthew Canzoneri, Seppo Honkapohja, and Michael Rauscher for their constructive criticisms. Besides, I would like to thank participants at the ZEI - Summer School 2002 on Monetary Theory and Policy in Bonn (D) for valuable contributions.

Received 10 March 2005, Accepted 7 December 2005

\section{References}

Aksoy, Yunus; de Grauwe, Paul and Dewachter, Hans: Do Asymmetries Matter for European Monetary Policy?, in: The European Economic Review, Vol 46, 2002, pp 443-469

Argy, Victor; McKibbin, Warwick and Siegloff, Eric: Exchange-Rate Regimes for a Small Economy in a Multi-Country World, in Princeton Studies in International Finance, No 67, Princeton University, New Jersey, 1989 
Barro, Robert and Gordon, David: A Positive Theory of Monetary Policy in a Natural Rate Model, in The Journal of Political Economy, Vol 91, 1983a, p 589-610

Barro, Robert and Gordon, David: Rules, Discretion and Reputation in a Model of Monetary Policy, in Journal of Monetary Economics, Vol 12, 1983b, p 101-121

Bayoumi, Tamim: A Formal Model of Optimum Currency Areas, in IMF Staff Papers, Vol 41, No 4, 1994, p 537-554

Beine, Michel and Docquier, Frédéric: A Stochastic Simulation Model of an Optimum Currency Area, in Open Economies Review, Vol 9, 1998, p 227-255

Broadbent, Ben and Barro, Robert J: Central Bank Preferences and Macroeconomic Equilibrium, in Journal of Monetary Economics, Vol 39, 1997, p 17-43

Buiter, Willem H and Miller, Marcus: Real Exchange Rate Overshooting and the Output Cost of Bringing down Inflation, in European Economic Review, Vol 18, 1982, p 85-123

Canzoneri, Matthew B and Gray, Joanna: Monetary Policy Games and the Consequences of Non-Cooperative Behavior, in International Economic Review, Vol 26, 1985, p 547-564

Canzoneri, Matthew B; Cumby, Robert E and Diba, Behzad T: The Need for International Policy Coordination: What's Old, What's New, What's Yet to Come?, in mimeo, first draft: November 9, 2001; this draft: December 3, 2001; presented at the ZEI Summer School (Bonn (D)) in 2002

Clarida, Richard; Gali, Jordi and Gertler, Mark: A Simple Framework for International Monetary Policy Analysis, in NBER Working Papers Series, Working Paper 8870, 2002

Dixit, Avinash: Games of Monetary and Fiscal Interactions in the EMU, in European Economic Review, Vol 45, 2001, p 589-613

Dornbusch, Rudiger; Favero, Carlo and Giavazzi, Francesco: Immediate Challenges for the European Central Bank, in Economic Policy: A European Forum, Vol 26, 1998, p 17-64

Frey, Rainer: Welfare Implications of the Design of a Currency Union in Case of Member Countries of Different Sizes and Output Persistence, in: Discussion Paper of the Economic Research Centre of the Deutsche Bundesbank, No. 15, 2004

Gali, Jordi and Monacelli, Tommaso: Monetary Policy and Exchange Rate Volatility in A Small Open Economy, in NBER Working Papers Series, Working Paper 8905, 2002

Gray, Joanna: Wage Indexation: A Macroeconomic Approach, in Journal of Monetary Economics, Vol 2, 1976, p 221-235

Gros, Daniel and Lane, Timothy: Monetary Policy Interaction Within or Without an Exchange-Rate Arrangement, in Open Economies Review, Vol 3, 1992, p 61-82

Gruner, Hans Peter: On the Role of Conflicting National Interests in the ECB Council, in CEPR Discussion Papers, No 2192, 1999

Hamada, Koichi: Alternative Exchange Rate Systems and the Interdependence of Monetary Policies, in National Monetary Policies and the International Financial System (editor: Aliber, Robert Z), Chicago, The University of Chicago Press, 1974, p 13-33

Hamada, Koichi: The Choice of International Monetary Regimes in a Context of Repeated 
Games, in Open Economies Review, Vol 9, 1998, p 417-445

Helpman, Elhanan: An Exploration in the Theory of Exchange Rate Regimes, in Journal in Political Economy, Vol 89, 1981, p 865-890

Horowitz, Ann R: Loss Functions and Public Policy, in Journal of Macroeconomics, Vol 9, No 4, 1987, p 489-504

IMF: Exchange Arrangements and Foreign Exchange Markets, in World Economic and Financial Surveys, IMF, Washington, 2003

Kydland, Finn and Prescott, Edward: Rules Rather Than Discretion: The Inconsistency of Optimal Plans, in The Journal of Political Economy 85, 1977, p 473-490

Lockwood, Ben; Miller, Marcus and Zhang, Lei: Designing Monetary Policy when Unemployment Persists, in Economica, Vol 65, 1998, p 327-345

Mundell, Robert A: A Theory of Optimum Currency Areas, in American Economic Review, Vol 51, No 3, 1961, p 657-664

Obstfeld, Maurice and Rogoff, Kenneth: Exchange Rate Dynamics Redux, in Journal of Political Economy, Vol 103, 1995, p 624-660

Obstfeld, Maurice and Rogoff, Kenneth: Risk and Exchange Rates, in NBER Working Papers Series, Working Paper 6694, 1998

Obstfeld, Maurice and Rogoff, Kenneth: New Directions for Stochastic Open Economy Models, in NBER Working Papers Series, Working Paper 7313, 1999

Oudiz, Gilles and Sachs, Jeffrey: International Policy Coordination in Dynamic Macroecomic Models, in International Economic Policy Coordination (editors: Buiter, Willem H and Marston, Richard C), Cambridge, Cambridge University Press, 1985

Persson, Torsten and Tabellini, Guido: Monetary Cohabitation in Europe, in NBER Working Papers Series, Working Paper 5532, 1996

Rogoff, Kenneth: The Optimal Degree of Commitment to an Intermediate Monetary Target, in The Quarterly Journal of Economics, Vol 100, 1985a, p 1169-1189

Rogoff, Kenneth: Can International Monetary Policy Cooperation be Counterproductive?, in Journal of International Economics, Vol 18, 1985b, p 199-217

Rotemberg, Julio and Woodford, Michael: Interest Rate Rules in an Estimated Sticky Price Model, in Monetary Policy Rules (editor: John B Taylor), NBER - Business Cycles Series, Volume 31, Chicago, University of Chicago Press, 1999, p 57-119

Svensson, Lars E. O.: Optimal Inflation Targets, 'Conservative' Central Banks, and Linear Inflation Contracts, in The American Economic Review, Vol 87, 1997, p 98-111

Von Hagen, Jürgen: EMU: Political Economic Issues and Challenges, in mimeo, February 1999b; presented at the ZEI Summer School (Bonn (D)) in 1999

Von Hagen, Jürgen: The Composition of Bank Councils for Heterogeneous Monetary Unions, in Regional Aspects of Monetary Policy in Europe (editors: von Hagen, Jürgen and Waller, Christopher J), Boston, Kluwer Academic Publishers, 2000, p 221-239

Woodford, Michael: Inflation Stabilization and Welfare, in NBER Working Papers Series, Working Paper 8071, 2001 


\section{Appendix}

\section{A. Monetary policy and the nominal and real exchange rate}

To derive the impact of monetary policy on the real exchange rate, first, the nominal exchange rate has to be considered.

It is assumed that, immediately after a monetary intervention, the nominal exchange rate jumps on its new long-term level, which is determined by purchasing-power parity. Additionally, nominal-exchange-rate shocks may occur at the beginning of period $t$. Thus, the relationship between the nominal exchange rate, the inflation rate and nominal-exchange-rate shocks is described by

$$
s_{t}=s_{t-1}+\left(\pi_{t}-\pi_{t}^{a}\right)+\eta_{t},
$$

where $s_{t}$ is the log of the nominal exchange rate in period $t, \pi_{t}\left(\pi_{t}^{a}\right)$ is the domestic (foreign) inflation rate, and $\eta_{t}$ is a iid speculative shock to the nominal exchange rate in period $t$ with mean zero and variance $\left(\sigma^{\text {nom }}\right)^{2}$.

At the beginning of a period, the price levels of the goods at home and abroad still correspond to those which were expected by the private sector in the preceding period. Thus, it is possible to write for the real exchange rate at the beginning of period $t$

$$
r_{t}=s_{t}+p_{t}^{a e}-p_{t}^{e}
$$

where $r_{t}$ is the log of the real exchange rate at the beginning of period $t$, and $p_{t}^{e}$ and $p_{t}^{a e}$ are the logarithms of the domestic and foreign price levels expected for period $t$ and, simultaneously, they are the actual price levels at the beginning of period $t$.

The expected price levels at home and abroad can be described as

$$
\begin{gathered}
p_{t}^{e}=p_{t-1}+\pi_{t}^{e}, \\
p_{t}^{a e}=p_{t-1}^{a}+\pi_{t}^{a e} .
\end{gathered}
$$

Inserting equations (a1), (a3) and (a4) into equation (a2), the real exchange rate may be rewritten as 


$$
r_{t}=s_{t-1}-p_{t-1}+p_{t-1}^{a}+\left[\left(\pi_{t}-\pi_{t}^{e}\right)-\left(\pi_{t}^{a}-\pi_{t}^{a e}\right)\right]+\eta_{t}
$$

Since the lagged values do not influence the results, one can simplify as follows:

$$
r_{t}=\left[\left(\pi_{t}-\pi_{t}^{e}\right)-\left(\pi_{t}^{a}-\pi_{t}^{a e}\right)\right]+\eta_{t} .
$$

\section{B. The Phillips-curve relationship under flexible exchange rates}

Under flexible exchange rates, output supply is a function of the real exchange rate. This relationship is derived below.

Labour demand and, with it, goods supply depends on the real wage (see Rogoff (1985a)). In an open economy, firms may sell their products both at home and abroad. Thus, the price that the firms charge for their products is a composite of domestic and foreign prices. ${ }^{1516}$ The composed price level has to be considered in Rogoff's optimality condition from profit-maximising firms:

$$
\begin{aligned}
& \beta_{0}+\log (1-\beta)+\beta \bar{q}+\beta t_{t}^{d}+\varepsilon_{t}=w_{t}-p_{t}^{s}, \\
& \text { with } p_{t}^{s}=\tau p_{t}+(1-\tau)\left(s_{t}+p_{t}^{a}\right),
\end{aligned}
$$

where $p_{t}^{s}$ is the composed price level of domestic goods sold at home and abroad, $p_{t}$ and $p_{t}^{a}$ are the actual prices of goods at home and abroad in period $t$, and $\tau$ is a weighting parameter.

After rearrangements, the composed price level can be expressed as

$$
p_{t}^{s}=\tau p_{t}+(1-\tau)\left(s_{t}+p_{t}^{a}-p_{t}+p_{t}\right)=p_{t}+(1-\tau) r_{t}^{\prime},
$$

where $r_{t}^{\prime}$ is the real exchange rate at the end of period $t$.

However, in this small model with its neglect of dynamics, the real exchange rate at the end of a period $t, r_{t}^{\prime}$, always equals zero. Thus, if we wish to model output effects that are triggered by real-exchange-rate movements, we have to refer to the real exchange rate at the beginning of the period, $r_{t}$ (see equation (a6)), which can be affected by monetary policy. Thus, we have to make a jump in the

\footnotetext{
${ }^{15}$ In the case of equal prices at home and abroad, there is no trade.

${ }^{16}$ Argy, McKibbin and Siegloff (1989) make the wage dependent on domestic and foreign prices. By doing so, they obtain an output-supply function that negatively depends on the real exchange rate.
} 
deduction: the real exchange rate at the end of a period $t, r_{t}^{\prime}$, is replaced by that at the beginning of the period, $r_{t}$ :

$$
p_{t}^{s}=p_{t}+(1-\tau) r_{t}
$$

And referring to the derivation by Rogoff (1985a), equation (a1) allows us to write the Phillips in the following way:

$$
y_{t}=\alpha\left(p_{t}^{s}-p_{t}^{s e}\right)
$$

and with equations (a9)

$$
y_{t}=\alpha\left(p_{t}+(1-\tau) r_{t}\right)-\alpha E_{t-1}\left(p_{t}+(1-\tau) r_{t}\right)=\alpha\left(p_{t}-p_{t}^{e}\right)+\alpha(1-\tau) r_{t}
$$

By analogy with the expected price level in equation (a3), the actual price level may be written in the following way:

$$
p_{t}=p_{t-1}+\pi_{t}
$$

With equations (a3), (a5) and (a12), the simplification of setting all lagged values zero and $\tau=n$, equation (a11) becomes

$$
y_{t}=\alpha\left(\pi_{t}-\pi_{t}^{e}\right)+\delta r_{t}+\varepsilon_{t}
$$

with $\delta=\alpha(1-n)$. 